\title{
Stefan Bechtold
}

\section{Die Grenzen zwingenden Vertragsrechts}

Ein rechtsökonomischer Beitrag zu einer Rechtsetzungslehre des Privatrechts

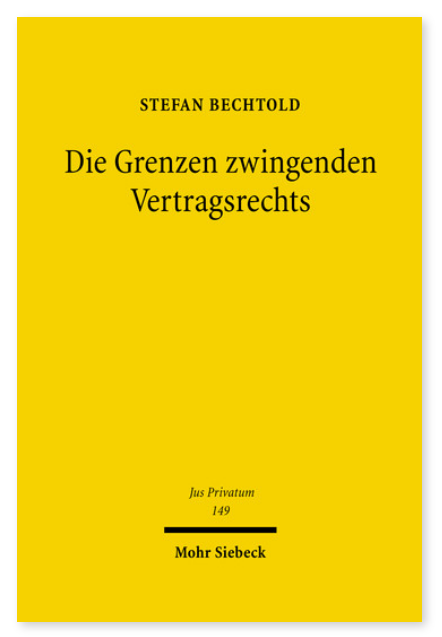

2010. XV, 425 Seiten. JusPriv 149

ISBN 978-3-16-151226-1

DOI 10.1628/978-3-16-151226-1

eBook PDF 129,00€

ISBN 978-3-16-150155-5

Leinen $129,00 €$
In vielen Bereichen des Privatrechts wird die Privatautonomie von Vertragsparteien zunehmend gesetzlich beschränkt. Stefan Bechtold zeigt an Beispielen aus dem allgemeinen Zivilrecht, dem Verbraucherschutzrecht sowie dem Gesellschafts- und Kapitalmarktrecht Grenzen auf, bei denen zwingendes Vertragsrecht als Regulierungsinstrument versagt. Dabei öffnet sich die Untersuchung dem heutigen Methodenapparat von »(behavioral) law and economics » in seiner ganzen Breite und Tiefe. Auf dieser Grundlage entwickelt der Autor Bausteine einer funktionalen Rechtsetzungslehre, welche die Vor- und Nachteile unterschiedlicher Regulierungsinstrumente im Privatrecht untersucht. Auch analysiert er, in welchem Umfang eine Integration ökonomischer und verhaltenswissenschaftlicher Erkenntnisse in rechtswissenschaftliche Untersuchungen möglich ist. Thematisiert werden damit auch die Grenzen sozialwissenschaftlicher Methoden.

Stefan Bechtold Geboren 1974; Studium der Rechtswissenschaft in Tübingen und Stanford; 2001 Promotion; 2005-2008 Mitarbeiter am Max-Planck-Institut zur Erforschung von Gemeinschaftsgütern in Bonn; 2009 Habilitation; Professor für Immaterialgüterrecht an der ETH Zürich.

Jetzt bestellen:

https://mohrsiebeck.com/buch/die-grenzen-zwingenden-vertragsrechts-9783161512261?no_cache=1 order@mohrsiebeck.com

Telefon: +49 (0)7071-923-17

Telefax: +49 (0)7071-51104 